\title{
EKSPLORASI ETNOMATEMATIKA PADA KAIN TENUN MASYARAKAT DESA LAMAKSENULU
}

\author{
Estevania Ferrer Mendoca ${ }^{1 *}$, Hermina Disnawati $^{2}$, Sulasri Suddin ${ }^{3}$ \\ Universitas Timor ${ }^{1,2,3)}$ \\ *estevaniamendoca@gmail.com ${ }^{1}$, disnawati@unimor.ac.id ${ }^{2}, \underline{\text { Sulasri.suddin@gmail.com }}{ }^{3}$
}

\begin{abstract}
InformasiArtikel Abstrak
Revisi:

28 Desember 2021

Diterima:

29 Desember 2021

Diterbitkan:

30 Desember 2021

\section{Kata Kunci}

Etnomatematika

Matematika

Kain Tenun

Bangun Datar

Etnomatematika merupakan salah satu cara pembelajaran matematika yang menghubungkan kebiasaan adat lokal dalam pembelajaran matematika. Dengan etnomatematika pengetahuan belajar matematika dapat dikembangkan melalui praktek budaya. Oleh karena itu, peserta didik diharapkan agar mampu memahami keterkaitan budaya dengan matematika. Salah satu objek etnomatematika adalah kain tenun. Kain tenun yang dimiliki setiap daerah bermacam-macam. Begitu juga dengan motif kain tenun masyarakat Desa Lamaksenulu dari daerah Belu, Nusa Tenggara Timur. Penelitian ini bertujuan untuk mengeksplorasi bentuk matematika apa saja yang ada pada kain tenun masyarakat Desa Lamaksenulu dari daerah Belu, Nusa Tenggara Timur. Penelitian ini menggunakan metode kualitatif dengan pendekatan etnografi. Teknik pengambilan data yang digunakan adalah dokumentasi, observasi dan wawancara. Analisis yang digunakan ialah analisis deskriptif agar dapat menyajikan informasi tentang keterkaitan matematika dan budaya. Dari hasil penelitian yang didapat disimpulkan bahwa terdapat hubungan kain tenun masyarakat Desa Lamaksenulu dengan matematika yaitu konsep bangun datar berbentuk seperti segi enam, belah ketupat, titik dan garis yang bisa dijadikan sebagai pembelajaran khususnya untuk siswa SMP dengan materi konsep bangun datar.
\end{abstract}

\begin{abstract}
Ethnomatematics is one way of leearning mathematics that connects local customs in learning mathematics. With ethnomatematics, knowledge of learning mathematics can be developed through cultural practices. Therefore, students are expected to be able to understand the relationship between culture and mathematics. One of the objects of ethnomatematics is woven cloth. Woven fabrics that are owned by each region vary. Likeiwise with the woven motifs of the Lamaksenulu Village community and the Belu area, East Nusa Tenggara. This study aims to explore what forms of mathematics exist in the woven fabrics of the Lamaksenulu Village community from the Belu area, East Nusa Tenggara. This study uses a qualitative method with an ethnographic approach. Data collection techniques used are documentation, observation and interviews. The analys used is descriptive analysis in order to present information about the the relationship between mathematics and culture. From the research results, it can be concluded that there is a relationship between the woven fabrics of the Lamaksenulu Village community and mathematics, namely the concept of flat shapes shaped like a hexagons, rhombuses, points and lines that can be used as learning, especially for junior high school students with the concept of flat shapes.
\end{abstract}

How to cite: Mendoca, E. F., Disnawati, H., \& Suddin, S. (2021). Eksplorasi Etnomatematika Pada Kain Tenun Masyarakat Desa Lamaksenulu. Math-Edu: Jurnal Ilmu Pendidikan Matematika, 6 (3), pp-pp. Doi: https://doi.org/10.32938/jipm.6.3.2021.123-131 


\section{Pendahuluan}

Indonesia merupakan negara kepulauan yang kaya akan budaya dimana masyarakatnya memiliki berbagai macam suku, agama dan kepercayaan yang dianut. Begitu pula dengan Pulau Timor yang merupakan salah satu wilayah Nusa Tenggara Timur. Tradisi dan budaya yang dimiliki hampir sama, namun terdapat salah satu budaya yang sudah turun temurun pada Masyarakat Timor adalah budaya menenun. Budaya menenun sampai saat ini masih di lakukan secara tradisional oleh Masyarakat Timor. Kebudayaan tidak dapat dipisahkan dari kehidupan manusia. Kebudayaan merupakan ciri khas manusia untuk mengadaptasikan diri dengan lingkungannya. Indonesia adalah negara yang memiliki berbagai kekayaan budaya seperti rumah adat, pakaian adat, upacara adat, seni musik, seni tari tradisional, seni rupa tradisional, suku bangsa, bahasa daerah dan kain tenun.

Indonesia merupakan negara yang terkenal dengan keanekaragaman budayanya (Rahayu, et al., 2020., Son, 2017). Seiring dengan perkembangan zaman, budaya-budaya Indonesia mulai punah. Tidak terkecuali, kehidupan anak-anak pun berubah, generasi yang baru dan akan datang cenderung tidak mengenal budaya sendiri contohnya seperti budaya kain tenun. Mereka cenderung lebih mengenal produk pakaian luar negeri yang berbau "kekinian" dibandingkan produk-produk yang memanfaatkan kain tenun khas Indonesia dikarenakan pengaruh perkembangan zaman lebih mendominasi. Jika hal ini terjadi, tidak menutup kemungkinan bahwa nantinya budaya sendiri yang akan punah secara perlahan-lahan. Untuk itu diperlukan suatu upaya mengingatkan kembali atau semakin mendekatkan orang Indonesia khususnya siswa dengan budayanya sendiri.

Salah satu cara mendekatkan kembali masyarakat dengan keanekaragaman budaya Indonesia adalah dengan mempertahankan kain tenun. Tibo (2017) mengatakan bahwa dalam aktivitas menenun (teun) kain Timor terdapat proses generalisasi yang berhubungan dengan pembuatan pola-pola pada tenunan baik pola bilangan maupun pola geometri seperti faktor bilangan genap/ganjil atau bilangan kelipatan yang terdapat pada pola secara mendatar dan secara membujur. Hal ini menunjukkan adanya nilai Etnomatematika yang terkandung dalam hasil tenun. Etnomatematika adalah matematika yang dipraktikkan oleh kelompok budaya seperti masyarakat perkotaan dan pedesaan, kelompok buruh, anak-anak dari kelompok usia tertentu, masyarakat lainnya menurut (D'Ambrosio, 2001:42).

Penelitian tentang etnomatematika kain tenun pernah dilakukan oleh Syahriannur (2019). Tujuan dari penelitian tersebut adalah untuk mengekplorasi contoh ide-ide matematika yang terdapat dalam motif kain songket Minang. Meskipun berupa hasil studi pustaka, didapati prinsip-prinsip geometri seperti simetri, transformasi, refleksi dan pengulangan dalam menghasilkan kain songket minangkabau. Begitu juga didapatkan konsep-konsep matematika matematika dalam motif kain songket minangkabau seperti garis lurus, garis lengkung, lingkaran dan bangun polygon seperti segitiga, segiempat, bentuk bintang, hexagon, octagon, piramid dan parallelogrammotif. Penelitian etnomatematika pernah dilakukan oleh (Rahayu et al. 2020). Tujuan dari penelitian ini untuk 
menggali dan mengeksplorasikan konsep matematika apa saja yang yang ada pada kain tenun Lipa Kaet dari Riung, Nusa Tenggara Timur. Hasil penelitian disimpulkan bahwa terdapat hubungan tenun Lipa Kaet dengan matematika dimana konsep bangun datar seperti berbentuk persegi panjang, belah ketupat, segitiga dan segienam juga terdapat dalam motif kain tenun Lipa Kaet.

Perbedaan penelitian yang dilakukan dengan penelitian sebelumnya terdapat pada bentuk motif kain dari masing-masing daerah. Kajian yang terbatas tentang motif kain tenun di Desa Lamaksenulu yang membuat peneliti tertarik untuk mengeksplorasi bentuk-bentuk dan pola kain tenun Masyarakat Desa Lamaksenulu sehingga dapat dijadikan sebagai sumber belajar pengembangan matematika kontekstual yang didasarkan pada keanekaragaman budaya. Alasan ini juga yang melatarbelakangi pendidikan khususnya pendidikan matematika untuk bagaimana mendekatkan masyarakat Indonesia dengan budaya melalui pendidikan matematika dengan kehidupan masyarakat sehari-hari.

\section{Metode}

Jenis penelitian yang digunakan dalam penelitian ini adalah penelitian kualitatif dengan pendekatan etnografi. Creswell (2012: 462) mengartikan etnografi adalah prosedur penelitian kualitatif untuk menggambarkan, menganalisa, dan menafsirkan bagian dari suatu perkumpulan kelompok budaya seperti pola perilaku, kepercayaan, dan bahasa yang berkembang dari waktu ke waktu. Metode pengumpulan data yang digunakan pada penelitian ini adalah metode observasi, wawancara dan dokumentasi. Data yang dikumpulkan tersebut dapat bersifat deskriptif dalam bentuk kata-kata atau gambar. Data bisa didapat dari hasil interview, catatan, observasi lapangan dan lain-lain.

Analisis data dilakukan dengan 3 tahap yaitu:

1. Reduksi data

Reduksi data merupakan kegiatan merangkum,memilih hal-hal yang pokok memfokuskan pada hal-hal yang penting. Dalam tahap reduksi data yang dilakukan adalah penyederhanaan, penggolongan, dan membuang yang tidak perlu sehingga data tersebut dapat menghasilkan informasi yang bermakna dan memudahkan dalam penarikan kesimpulan.

2. Penyajian Data

Setelah mereduksi data tahap selanjutnya yang dilakukan adalah penyajian data. Penyajian data dalam tahap ini, data dokumentasi dari hasil observasi disajikan. Data disajikan dalam bentuk uraian singkat, bagan dan lain sebagainya tujuannya agar mempermudah peneliti dalam memahami penyajian data.

3. Kesimpulan dan verifikasi

Tahap penarikan kesimpulan dan verifikasi ini merupakan tahap akhir yang dilakukan dengan melihat hasil reduksi dan penyajian data serta tetap mengacu pada tujuan dari penelitian ini. 


\section{Hasil Penelitian dan Pembahasan}

Masyarakat Desa Lamaksenulu sebagian besar mengetahui bahwa menenun adalah aktivitas yang dilakukan untuk membuat pakaian daerah, namun hasil penelitian didapati bahwa aktivitas menenun, motif Kalor dan Oen suin terdapat beberapa unsur matematika.

Hasil penelitian ini, sesuai dengan penelitian terdahulu yang penah dilakukan oleh Rahayu et al., (2020) bahwa terdapat hubungan tenun Lipa Kaet dengan matematika dimana konsep bangun datar seperti berbentuk persegi panjang, belah ketupat, segitiga dan segienam juga terdapat dalam motif kain tenun Lipa Kaet. Sedangkan penelitian lain yang pernah dilakukan oleh Doli \& Mei, (2018) menyatakan bahwa tenun Lao Lio Suku Mbuli memiliki hubungan dengan pembelajaran matematika pada materi geometri.

Adapun konsep matematika yang terdapat dalam aktivitas menenun motif kalor dan oen suin dapat dilihat pada uraian sebagai berikut:

\section{Konsep Mengukur}

Mengukur berkaitan dengan panjang, lebar suatu tenunan yang dihasilkan, aktivitas mengukur yang digunakan oleh penenun masyarakat Desa Lamaksenulu masih tradisional dengan menggunakan ukuran jengkalan orang dewasa dengan lebarnya 4 jengkal sedangkan panjangnya tujuh jengkal, satu jengkal ini setara dengan $20 \mathrm{~cm}$.

Menurut Padafing (2019) mengemukakan etnomatematika merupakan cara-cara khusus yang dipakai oleh suatu kelompok budaya atau masyarakat tertentu dalam aktivitas matematika. Aktivitas matematika merupakan aktivitas yang terjadi dari sebuah proses pengalaman nyata dalam kehidupan sehari-hari kedalam matematika atau sebaliknya, meliputi aktivitas mengelompokkan, berhitung, mengukur, merancang bangunan atau alat, membuat pola, membilang, menentukan lokasi, bermain, menjelaskan dan sebagainya.

\section{Garis}

Pada aktivitas menenun ini, mengaplikasikan konsep garis lurus untuk membuat batasan pada motif apit atau benang warna yang menutupi tepi motif. Menurut Bili (2019: 119) garis adalah konsep abstrak yang bentuknya lurus, memanjang kedua arah, tidak terbatas dan tidak memiliki tebal. Garis lurus merupakan kurva lurus yang tidak berujung dan tidak berpangkal. Artinya dapat di perpanjang kedua arahnya.

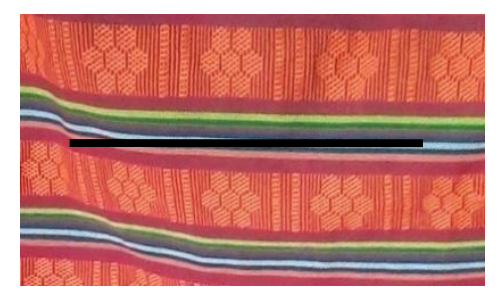




\section{Gambar 1. Sketsa Garis}

\section{Segi Enam Beraturan}

Segi enam beraturan atau hexagon merupakan segi enam yang keenam sisinya sama panjang dan memiliki enam sudut yang sama besar.

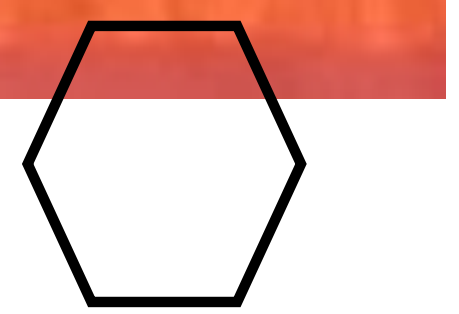

Gambar 2. Sketsa Segi Enam Beraturan

\section{Belah ketupat}

Belah ketupat adalah jajar genjang yang keempat sisinya sama panjang, dan setiap sudut dibagi dua sama besar oleh diagonal-diagonalnya serta diagonal berpotongan saling tegak lurus.

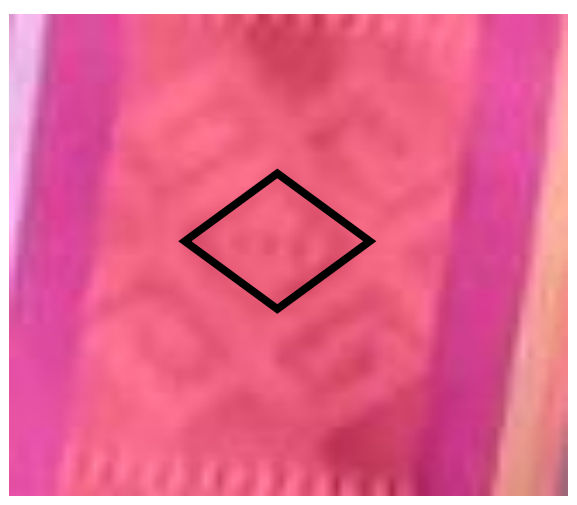

Gambar 3. Sketsa Belah Ketupat

\section{Titik}

Titik merupakan objek yang memiliki kedudukan tapi tidak mempunyai ukuran. Dalam aktivitas menenun, penenun mengaplikasikan konsep titik pada corak benang warna pada bagian pola apit kiri maupun bagian pola apit kanan yang mengapit motif induk.

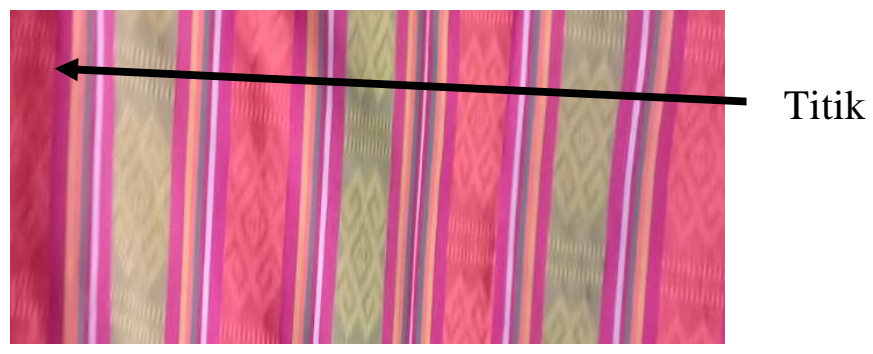

Gambar 4. Sketsa Titik 
Tabel 1 berikut ini merupakan rekapitulasi konsep matematika yang terdapat pada kain tenun masyarakat desa Lamaksenulu.

Tabel 1. Rekapitulasi Konsep Matematika

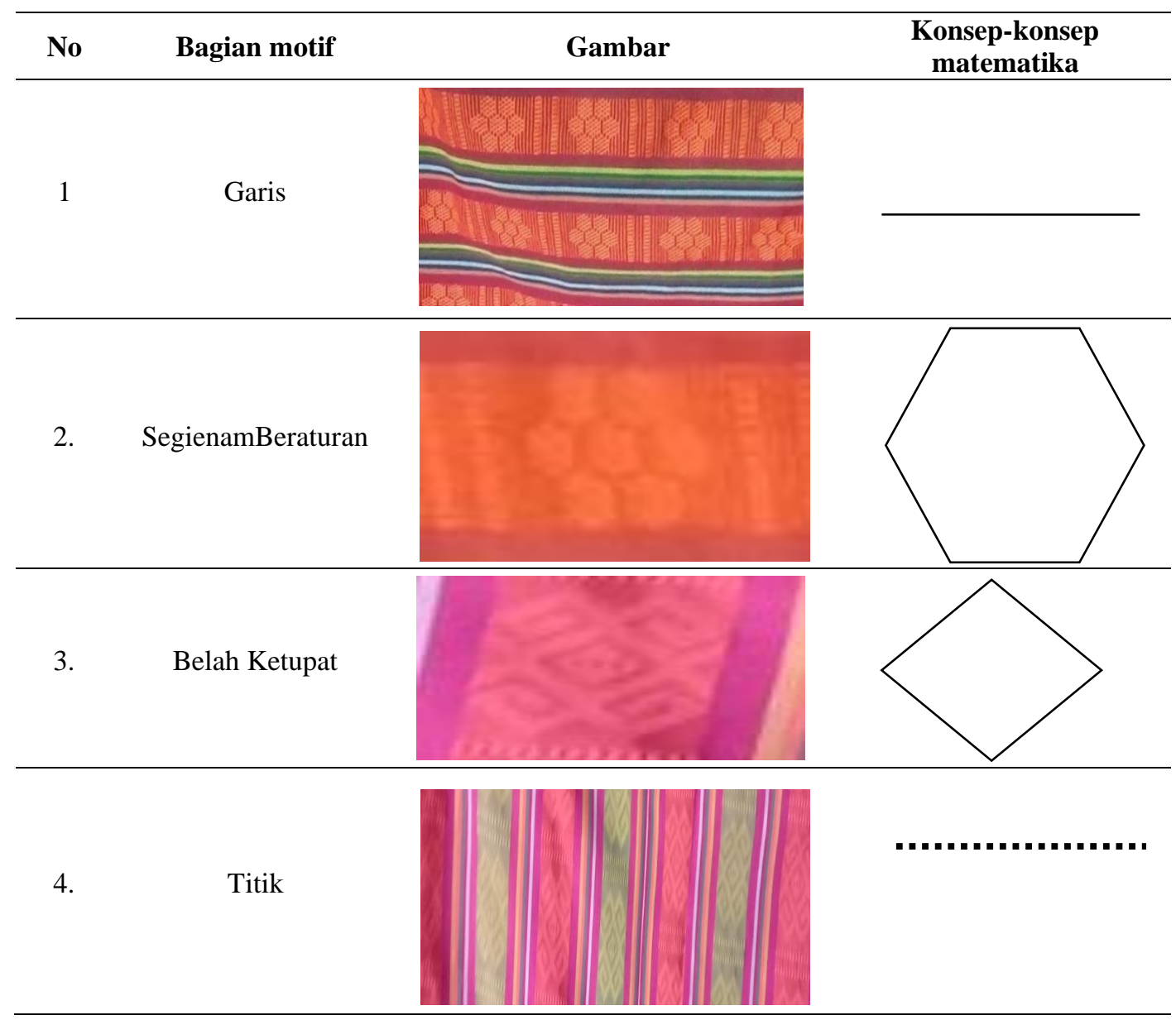

Berdasarkan pada penyajian data yang memuat antara keterkaitan dalam aktivitas pembuatan motif kain tenun kalor dan motif kain oen suin maka pada kesimpulan hasil penelitian terdapat konsep matematika saat proses pembuatan motif kain tenun.

Pada hasil penelitian menunjukkan bahwa aktivitas menenun pada proses pembuatan motif kalor dan motif oen suin terdapat konsep matematika yaitu:

1. Aktivitas mengukur, penenun mengukur menggunakan satuan tradisional jengkalan orang dewasa untuk mengukur panjang dan lebar kain tenun.

2. Konsep garis pada benang warna yang digunakan penenun pada motif pola apit.

3. Konsep bangun datar segi enam beraturan pada motif yang dihasilkan.

4. Konsep bangun datar belah ketupat pada motif yang dihasilkan. 
5. Konsep titik penenun mengaplikasikan konsep titik pada corak benang warna.

Menurut Juano \& Jediut, (2019) menyatakan dalam hasil penelitiannya bahwa terdapat bentukbentuk etnomatematika pada budaya masyarakat Manggarai yang terdapat dalam aktivitas menenun, upacara adat, anyaman, perlengkapan rumah tangga, bangunan, kegiatan bertani dan alat musik tradisional. Terdapat berbagai konsep-konsep geometri matematika SD yang meliputi segitiga, persegi panjang, belah ketupat, segi enam, lingkaran, balok, kerucut dan tabung.

Pada penelitian ini, peneliti juga mengaitkan etnomatematika kain tenun Lamaksenulu dengan materi pembelajaran di sekolah seperti tampak pada tabel 2.

Tabel 2. Kaitan Hasil Eksplorasi dengan Matematika Sekolah

\begin{tabular}{|c|c|c|}
\hline \multirow{2}{*}{\multicolumn{2}{|c|}{$\begin{array}{l}\text { Materi Pembelajaran } \\
\text { Aritmetika Sosial }\end{array}$}} & Contoh Penerapan Etnomatematika \\
\hline & & Contoh Soal: \\
\hline & $\begin{array}{l}\text { Harga penjualan dan } \\
\text { pembelian }\end{array}$ & $\begin{array}{l}\text { Bu Eni dari desa Lamaksenulu ingin menenun kain tenun dengan motif } \\
\text { kalor dan oen suin. Untuk membuat satu kain dibutuhkan } 25 \text { kepala benang. }\end{array}$ \\
\hline & $\begin{array}{l}\text { Keuntungan, kerugian, } \\
\text { dan impas }\end{array}$ & $\begin{array}{l}\text { Harga per kepala benang Rp.5000. Berapa banyak uang yang dibutuhkan } \\
\text { untuk membuat } 3 \text { kain tenun? }\end{array}$ \\
\hline & Presentase untung dan & Diketahui: \\
\hline & rugi & 1) 1 kain tenun dibutuhkan 25 kepala benang \\
\hline & Diskon & 2) Harga kepala benang Rp. 5.000/kepala \\
\hline & Pajak & Ditanya: Berapa banyak uang yang dibutuhkan untuk membuat 3 kain \\
\hline & Bruto, tara dan neto & tenun? \\
\hline \multirow{3}{*}{\multicolumn{2}{|c|}{ g) $\mathrm{Bu}$}} & Jawab: \\
\hline & & $3 \times 25=75$ \\
\hline & & $75 \times$ Rp. $5.000=$ Rp. 375.000 \\
\hline \multirow{2}{*}{\multicolumn{2}{|c|}{$\begin{array}{l}\text { Bangun Datar (Segi Empat } \\
\text { dan Segitiga) }\end{array}$}} & Belah Ketupat \\
\hline & & Contoh soal \\
\hline & $\begin{array}{l}\text { Pengertian segi empat } \\
\text { dan segitiga } \\
\text { Jenis-jenis dan sifat- } \\
\text { sifat bangun datar }\end{array}$ & D. \\
\hline & $\begin{array}{l}\text { Keliling dan luas segi } \\
\text { empat dan segitiga }\end{array}$ & $\begin{array}{l}\text { Panjang kain tenun motif kalor diatas adalah } 140 \mathrm{~cm} \text {. pada kain tenun } \\
\text { terdapat bentuk belah ketupat yang memanjang. Jika panjang diagonal }\end{array}$ \\
\hline & Menaksir luas bangun & $\begin{array}{l}\text { sebuah belah ketupat } 14 \mathrm{~cm} \text {. Berapa banyak motif belah ketupat pada kain } \\
\text { tenun kalor? }\end{array}$ \\
\hline & & Diketahui: \\
\hline & & $\begin{array}{l}\text { 1) Panjang kain tenun motif kalor diatas } 140 \mathrm{~cm} \text {. pada kain tenun terdapat } \\
\text { bentuk belah ketupat yang memanjang. }\end{array}$ \\
\hline & & 2) Panjang diagonal sebuah belah ketupat $14 \mathrm{~cm}$. \\
\hline & & Ditanya: \\
\hline & & Berapa banyak motif belah ketupat pada kain tenun kalor? \\
\hline & & Jawab: \\
\hline & & $140: 14=10$ \\
\hline \multicolumn{2}{|c|}{ Bangun Ruang Sisi Datar } & Segi Enam Beraturan \\
\hline & $\begin{array}{l}\text { Kubus, balok, prisma, } \\
\text { dan limas }\end{array}$ & Contoh soal \\
\hline b) & $\begin{array}{l}\text { Jaring-jaring: kubus, } \\
\text { balok, prisma, dan } \\
\text { limas. }\end{array}$ & $\begin{array}{lll}0 & 0 & 0 \\
0 & 0 & 0\end{array}$ \\
\hline c) & $\begin{array}{l}\text { Luas permukaan: kubus, } \\
\text { balok, prisma, dan } \\
\text { limas. }\end{array}$ & \\
\hline d) & $\begin{array}{l}\text { Volume: kubus, balok, } \\
\text { prisma, dan limas. }\end{array}$ & $\begin{array}{l}\text { Panjang kain tenun motif oen suin diatas adalah } 150 \mathrm{~cm} \text {. Pada kain tenun } \\
\text { terdapat motif segi enam yang mempunyai sisi sebesar } 5 \mathrm{~cm} \text {, berapa segi }\end{array}$ \\
\hline e) & Volume bangun ruang & enam yang terdapat pada kain tenun oen suin? \\
\hline
\end{tabular}


tak beraturan

Diketahui:

- $\quad$ Panjang kain tenun motif oen suin diatas $150 \mathrm{~cm}$

- $\mathrm{S}=5 \mathrm{~cm}$

Ditanya:

berapa segi enam yang terdapat pada kain tenun oen suin?

Jawab:

$\mathrm{K}=6 \times \mathrm{S}$

$\mathrm{K}=6 \times 5=30 \mathrm{~cm}$

$\mathrm{X}=150: 30=5$

\section{Kesimpulan}

Berdasarkan hasil penelitian eksplorasi etnomatematika ini dapat disimpulkan bahwa terdapat konsep matematika pada kain tenun masyarakat Desa Lamaksenulu, baik pada proses awal maupun tahapan proses menenun. Konsep matematika pada proses awal menenun adalah panjang dan lebar tenunan, dengan menggunakan ukuran jengkalan orang dewasa dengan lebarnya 4 jengkal, dan panjangnya 7 jengkal. 1 jengkal ini sama dengan $20 \mathrm{~cm}$. Sedangkan konsep matematika pada setiap setiap tahap dan proses pembuatan adalah pemilihan benang pada kombinasi warna kain yang cocok, konsep kesebangunan dan pengukuran, bangun datar yang kongruen, bangun datar, garis sejajar, belah ketupat, garis, segi enam beraturan, dan belah ketupat. Terdapat kaitan etnomatematika kain tenun Lamaksenulu dengan materi pembelajaran di sekolah.

\section{Rekomendasi}

Direkomendasikan kepada pencinta etnomatematika untuk mengkaji lebih komprehensif tentang konsep matematika pada kain tenun masyarakat Desa Lamaksenulu, dan selanjut dapat menerapkan konsep-konsep matematika tersebut dalam proses pembelajaran matematika di sekolah.

\section{Referensi}

Astuti, S. (2019). Eskplorasi Etnomatematika Kain Ulos Batak Toba Untuk Mengungkap Nilai Filosofi Konsep Matematika. Jurnal MathEducation Nusantara, 2(1), 45-50.

Avelia, L. T., Nugraheni, F. A., \& Palma. D. I. (2019). Etnomatematika Pada Kain Tapis Lampung Motif Pucuk Rebung. In ProSANDIKA UNIKAL (Prosiding Seminar Nasional Pendidikan Matematika Universitas Pekalongan) (Vol. 1, pp. 373-382).

Bili, F. M., Sujadi, A. A., \& Arigiyati, T. A. (2019). Identifikasi Etnomatematika pada Motif Kain Tenun Sumba Barat Daya. UNION: Jurnal Ilmiah Pendidikan Matematika, 7(1), 115-124.

Creswell, J. W. 2012. Educational research: planning, conducting, and evaluating quantitative and qualitative research. New Jersey: Person Education, Inc.

Doli, MSa'oS. \& Mei, A. 2018. Eksplorasi Matematika Symbol Geometri pada Tenun Lawo Nggela Leo. Jupika: Jurnal Pendidikan Matematika, 1(1), 1-9.

Hartoyo, A. (2012). Eksplorasi Etnomatematika Pada Budaya Masyarakat Dayak Perbatasan Indonesia-Malaysia Kabupaten Sanggau Kalbar. Jurnal Penelitian Pendidikan, 13(1), 14-23. 
Hasratuddin, H. \& Mujib, A. (2019). Eksplorasi Etnomatematika Kain Tenun Masyarakat Melayu Kota Tebing Tinggi. Jurnal MathEducation Nusantara, 2(1), 64-71.

Juano, A. \& Jediut, M. (2019). Eksplorasi Etnomatematika dan Hubungannya dengan Konsep Geometri pada Matematika Sekolah Dasar dalam Budaya Masyarakat Manggarai. Jurnal Pendidikan dan Kebudayaan Missio, 11(2), 270-278.

Mahuda, I. (2020). Eksplorasi Etnomatematika Pada Motif Batik Lebak Dilihat Dari Sisi Nilai Filosofi dan Konsep Matematis. Jurnal Lebesgue: Jurnal Ilmiah Pendidikan Matematika, Matematika dan Statistika, 1(1), 29-38.

Padafing A, (2019). Eksplorasi Etnomatematika dalam Moko dan Kain Tenun Motif Kui pada Kebudayaan Masyarakat Alor Suku Abui. Math-Edu: Jurnal Ilmu Pendidikan Matematika, 4(1), 1-8.

Rahayu, A. P., Snae, M., \& Bani. S, (2020). Etnomatematika Pada Kain Tenun Lipa Kaet. MEGA:Jurnal Pendidikan Matematika, 1(1), 16-24.

Son, A. L. (2017). Study Ethnomatematics: Pengungkapan Konsep Matematika dan Karakter Siswa pada Permainan Kelereng Masyarakat Suku Dawan. Journal of Medives, 1(2), 100-110.

Syahriannur, S. (2019). Eksplorasi Etnomatematika Kain Songket Minang Kabau Untuk Mengungkap Nilai Filosofi Konsep Matematika. Jurnal MathEducation Nusantara, 2(1), 58-63.

Tibo, D. B. S. (2017). Eksplorasi Etnomatematika Pada Aktivitas Menenun (Teun) Masyarakat Insana Utara. [Skripsi]. Universitas Timor.

Ulum, B. (2018). Etnomatematika Pasuruan: Eksplorasi Geometri untuk Sekolah Dasar pada Motif Pasedahan Suropati. Jurnal Review Pendidikan Dasar: Jurnal Kajian Pendidikan dan Hasil Penelitian, 4(2), 686-696.

Yudianto, E., Susanto, S., \& Priciliya, S. (2020). Etnomatematika pada Batik Lukis Daun Singkong di Rumah Produksi Daweea Batik Bondowoso. Jurnal Elemen, 6(2), 199-210. 